\title{
DIALysis or not: Outcomes in older kidney patients with GerlatriC Assessment (DIALOGICA): rationale and design
}

Mathijs van Oevelen ${ }^{1 *}$ (D), Alferso C. Abrahams², Willem Jan W. Bos ${ }^{1,3}$, Mariëlle H. Emmelot-Vonk ${ }^{4}$, Simon P. Mooijaart ${ }^{5}$, Merel van Diepen ${ }^{6}$, Brigit C. van Jaarsveld ${ }^{7}$, Anita van Eck van der Sluijs², Carlijn G. N. Voorend ${ }^{1}$, Marjolijn van Buren ${ }^{1,8}$ and on behalf of the DIALOGICA study group

\begin{abstract}
Background: The incidence and prevalence of older patients with kidney failure who are dependent on dialysis is increasing. However, observational studies showed limited or no benefit of dialysis on mortality in subgroups of these patients when compared to conservative care. As the focus is shifting towards health-related quality of life (HRQoL), current evidence of effects of conservative care or dialysis on HRQoL in older patients is both limited and biased. Dialysis comes with both high treatment burden for patients and high costs for society; better identification of patients who might not benefit from dialysis could result in significant cost savings. The aim of this prospective study is to compare HRQoL, clinical outcomes, and costs between conservative care and dialysis in older patients.

Methods: The DIALysis or not: Outcomes in older kidney patients with GerlatriC Assessment (DIALOGICA) study is a prospective, observational cohort study that started in February 2020. It aims to include 1500 patients from 25 Dutch and Belgian centres. Patients aged $\geq 70$ years with an eGFR of $10-15 \mathrm{~mL} / \mathrm{min} / 1.73 \mathrm{~m}^{2}$ are enrolled in the first stage of the study. When dialysis is initiated or eGFR drops to $10 \mathrm{~mL} / \mathrm{min} / 1.73 \mathrm{~m}^{2}$ or lower, the second stage of the study commences. In both stages nephrogeriatric assessments will be performed annually, consisting of questionnaires and tests to assess most common geriatric domains, i.e. functional, psychological, somatic, and social status. The primary outcome is HRQoL, measured with the Twelve-item Short-Form Health Survey. Secondary outcomes are clinical outcomes (mortality, hospitalisation, functional status, cognitive functioning, frailty), costeffectiveness, and decisional regret. All outcomes are (repeated) measures during the first year of the second stage. The total follow-up will be a maximum of 4 years with a minimum of 1 year in the second stage.

Discussion: By generating more insight in the effects of conservative care and dialysis on HRQoL, clinical outcomes, and costs, findings of this study will help patients and physicians make a shared decision on the best individual treatment option for kidney failure.

Trial registration: The study was registered in the Netherlands Trial Register (NL-8352) on 5 February 2020.

Keywords: Costs and cost analysis, Dialysis, Frailty, geriatric assessment, Kidney failure, chronic, Mortality, Quality of life
\end{abstract}

\footnotetext{
*Correspondence: M.van_Oevelen@lumc.nl

'Department of Internal Medicine, Leiden University Medical Center,

Albinusdreef 2, 2333 ZA Leiden, The Netherlands

Full list of author information is available at the end of the article
}

(C) The Author(s). 2021 Open Access This article is licensed under a Creative Commons Attribution 4.0 International License, which permits use, sharing, adaptation, distribution and reproduction in any medium or format, as long as you give appropriate credit to the original author(s) and the source, provide a link to the Creative Commons licence, and indicate if changes were made. The images or other third party material in this article are included in the article's Creative Commons licence, unless indicated otherwise in a credit line to the material. If material is not included in the article's Creative Commons licence and your intended use is not permitted by statutory regulation or exceeds the permitted use, you will need to obtain permission directly from the copyright holder. To view a copy of this licence, visit http://creativecommons.org/licenses/by/4.0/ The Creative Commons Public Domain Dedication waiver (http://creativecommons.org/publicdomain/zero/1.0/) applies to the data made available in this article, unless otherwise stated in a credit line to the data. 


\section{Background}

In the Netherlands, over 6200 patients (358 per million population) with kidney failure are currently dependent on dialysis with an annual incidence of over 1650 patients (95 per million population) [1]. The proportion of older patients has risen over the years and in 2019 45\% of the incident dialysis patients were 70 years or older [2]. After dialysis initiation, the overall mortality in this age group is high: $18 \%$ in the first year, $72 \%$ after 5 years [2]. A Dutch retrospective single-centre study showed no survival benefit from dialysis initiation for patients aged 80 years or older and in those above 70 years with severe comorbidity, compared to conservative care $(\mathrm{CC})$ [3]. These results were confirmed by a prospective multicentre study performed in the Netherlands [4]. Results such as these have shifted the focus from mortality towards health-related quality of life (HRQoL) as the most important outcome [5]. Dialysis is associated with a high treatment burden in older patients when compared to CC $[6,7]$. A recent meta-analysis reviewed 11 studies comparing HRQoL between older patients treated with CC or dialysis [7]. All studies had a small sample size, eight were single-centre, and eight were highly susceptible to selection bias and/or confounding. Thus, current evidence for the effects of CC or dialysis on HRQoL is both limited and biased. Despite these limitations, the authors conclude that $\mathrm{CC}$ has the potential to achieve similar HRQoL as dialysis.

Outcomes such as survival and HRQoL might differ greatly among older patients with kidney failure due to substantial heterogeneity with respect to functional and cognitive impairment and frailty. Establishing which of these conditions are associated with poor outcome may help to identify those patients at highest risk and thus guide informed treatment decisions [8]. To do this, some authors suggest tailoring the comprehensive geriatric assessments used in geriatric care to routine kidney failure care [9]. However, studies showing the benefit of these assessments on outcomes, such as survival and HRQoL, in these patients are lacking.

Besides the impact on survival and HRQoL, dialysis is also a highly expensive treatment: the costs in the Netherlands approximate $€ 92,000$ per patient per year, making it among the most expensive treatment in internal medicine, both per individual patient as in total treatment costs [10]. If dialysis treatment appears to yield little or no benefit in selected older and/or frail patients, such as improved survival or HRQoL, CC could be considered more often as the preferred treatment option. This may result in significant cost savings for treatment of kidney failure.

Therefore, large and well-designed, prospective, multicentre studies with sufficient follow-up in older patients treated with CC or dialysis are needed. The DIALysis or not: Outcomes in older kidney patients with GerIatriC Assessment (DIALOGICA) study aims to compare HRQoL, clinical outcomes, and financial costs between $\mathrm{CC}$ and dialysis in patients of 70 years or older with kidney failure. Secondly, the study aims to associate clinical and geriatric patient characteristics in the decisionmaking trajectory with these outcomes. Our hypothesis is that CC is associated with comparable HRQoL, comparable clinical outcomes, and lower costs, compared to dialysis in subgroups of older patients with kidney failure.

\section{Methods}

Study design

DIALOGICA is a multicentre, prospective, observational cohort study comparing CC with dialysis. The first patient was recruited in February 2020. The study aims to include 1500 patients from at least 25 academic and non-academic centres in the Netherlands and Belgium. DIALOGICA is one of the Leading the Change healthcare evaluation projects. Leading the Change finances and guides several healthcare evaluation projects in the Netherlands. The programme is financed by Dutch health insurers and aims to increase and implement acquired knowledge from these projects, thereby increasing the effectiveness of the Dutch healthcare system.

The study consists of two stages (Fig. 1). Patients remain in the first stage as long as their estimated glomerular filtration rate (eGFR), as calculated by the Chronic Kidney Disease Epidemiology Collaboration (CKD-EPI) formula or using mean urea and creatinine clearances in 24-h urine collections, stays above $10 \mathrm{~mL} /$ $\min / 1.73 \mathrm{~m}^{2}$. The second stage commences at the start of dialysis or when the eGFR drops to or below $10 \mathrm{~mL} /$ $\mathrm{min} / 1.73 \mathrm{~m}^{2}$. This creates two groups (patients treated with either dialysis or $\mathrm{CC}$ ) which are used as the main determinant for the study.

DIALOGICA is aimed to run for a total of 4 years with a minimum follow-up of 1 year in the second stage. The study is conducted according to the principles of the Declaration of Helsinki and the ICH-GCP guidelines. Primary ethical approval was obtained from the medical research ethics committee of the The Hague region (METC Zuidwest Holland) on May 24th 2019 (reference number 19-071). Local medical research ethics committees in participating centres will also be asked for local ethical approval. The study is registered in the Netherlands Trial Register under NL-8352.

\section{Study population}

Inclusion criteria are age of 70 years and older and an eGFR between 10 and $15 \mathrm{~mL} / \mathrm{min} / 1.73 \mathrm{~m}^{2}$ at the moment of inclusion. Due to the nature of the assessments that will be performed in this study (described in detail later), 


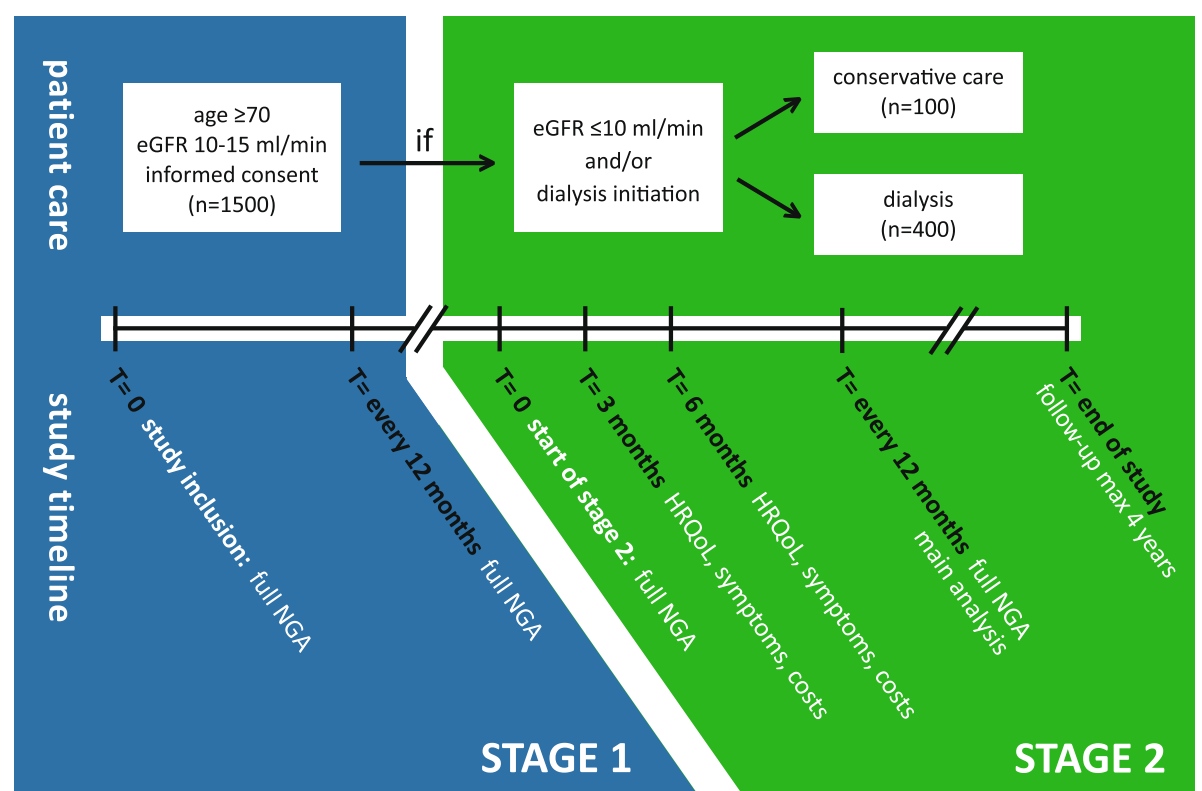

Fig. 1 Study flow chart. Abbreviations: eGFR estimated Glomerular Filtration Rate, HRQoL Health-Related Quality of Life, NGA NephroGeriatric Assessment

illiterate patients and those unable to speak Dutch will be excluded. All patients have to provide written informed consent. When a patient appears to have severe cognitive impairment, a geriatrician will judge if a patient is mentally competent to provide the required consent.

\section{Data registration}

At baseline, all relevant demographical and clinical data will be collected. In the first stage of the study, a followup visit will be scheduled once-yearly until the start of the second stage. In the second stage, data collection will be performed at start, after 3 months, 6 months, 12 months, and thereafter annually until end of follow-up or end of the study. All data will be recorded in a database developed in collaboration with Nefrovisie. Nefrovisie is the Dutch Quality Institute for Nephrology which hosts the Renine-database, in which all Dutch patients on kidney replacement therapy are registered. Upon consent, data for DIALOGICA will be linked to the Renine-database and the databases of three Dutch studies with similar or complementary study aims and outcomes: the Dutch nOcturnal and hoME dialysis Study To Improve Clinical Outcomes (DOMESTICO) study will compare HRQoL, clinical outcomes and costs in home dialysis patients with in-centre haemodialysis patients; the Pathway for OLDer patients with End-stage Renal disease (POLDER) project will assess the feasibility of implementing a geriatric assessment in routine predialysis care for older patients with an eGFR $<20 \mathrm{~mL} /$ $\mathrm{min} / 1.73 \mathrm{~m}^{2}$ and the Optimizing Access Surgery In Senior haemodialysis patients (OASIS) study will compare three strategies of vascular access in older patients using a randomised design [11-13]. The DIALOGICA database will be archived for future research during a minimum of 15 years after the completion of this study.

\section{Nephrogeriatric assessment}

To assess the most common geriatric domains (i.e. functional, psychological, somatic, and social status) and the study's outcome measures (i.e. HRQoL, clinical outcomes, and costs), a geriatric assessment tailored to the kidney failure population will be used. It is derived from the consensus-based test set used in a pilot study [11]. This nephrogeriatric assessment (NGA) consists of a combination of 12 questionnaires and seven tests and assessments (Table 1). Nine questionnaires are answered independently by the patient at home and three are conducted by an interviewer. All of the tests and assessments are performed in the participating centres. The NGA is performed at baseline and at a yearly interval during the first stage. Upon entering the second stage, a new NGA will be performed, repeated again at yearly intervals. The questionnaires on HRQoL, symptoms and costs are also repeated after 3 and 6 months into the second stage. To minimise inter-observer bias, the tests will be performed by trained geriatric or (pre) dialysis nurses only.

\section{Functional status}

Functionality will be assessed by using four instruments. Firstly, the Activity of Daily Living Scale by Katz et al. assesses the patient's ability to perform activities of daily living independently [14]. It ranks adequacy of performance 


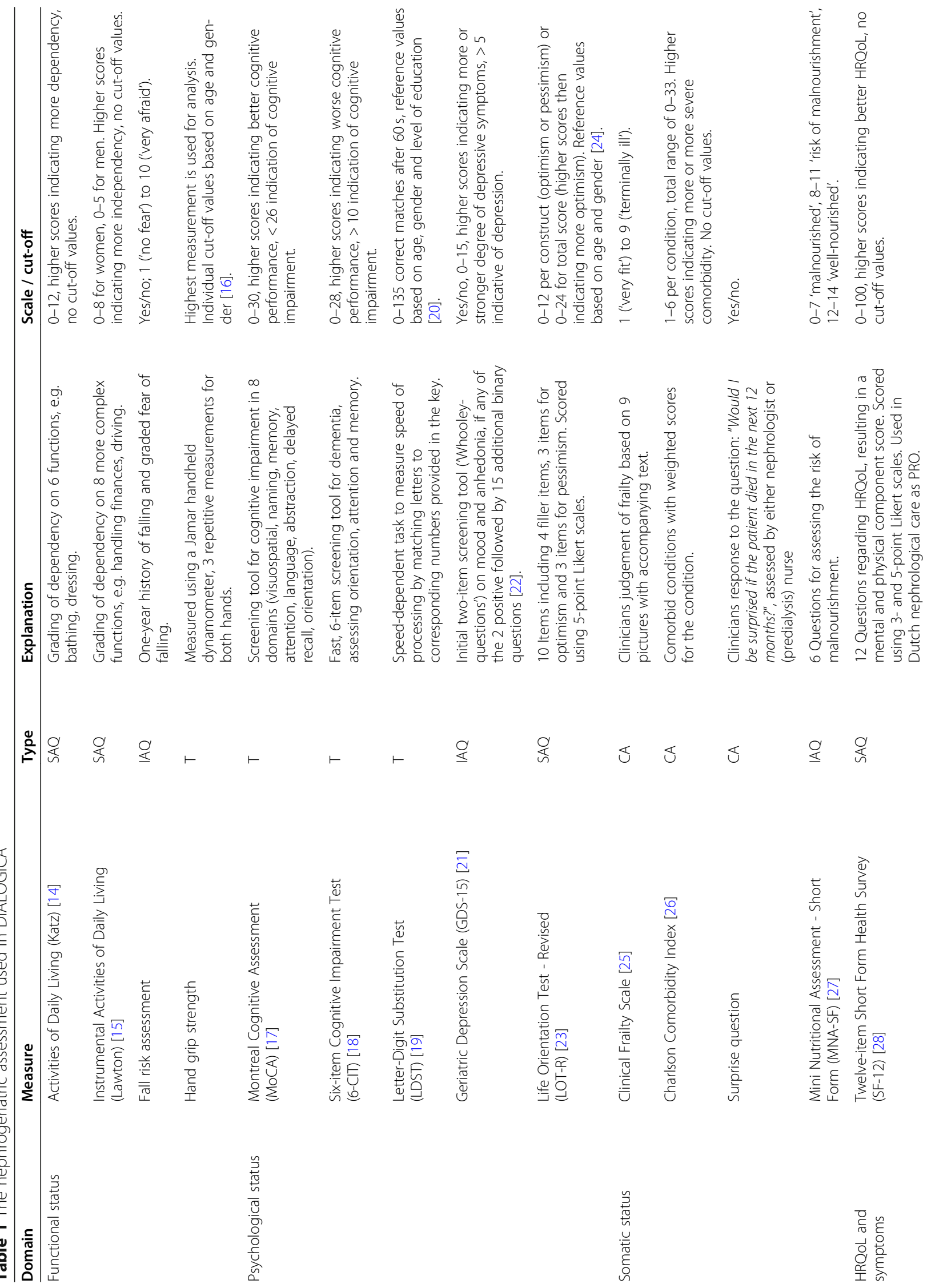




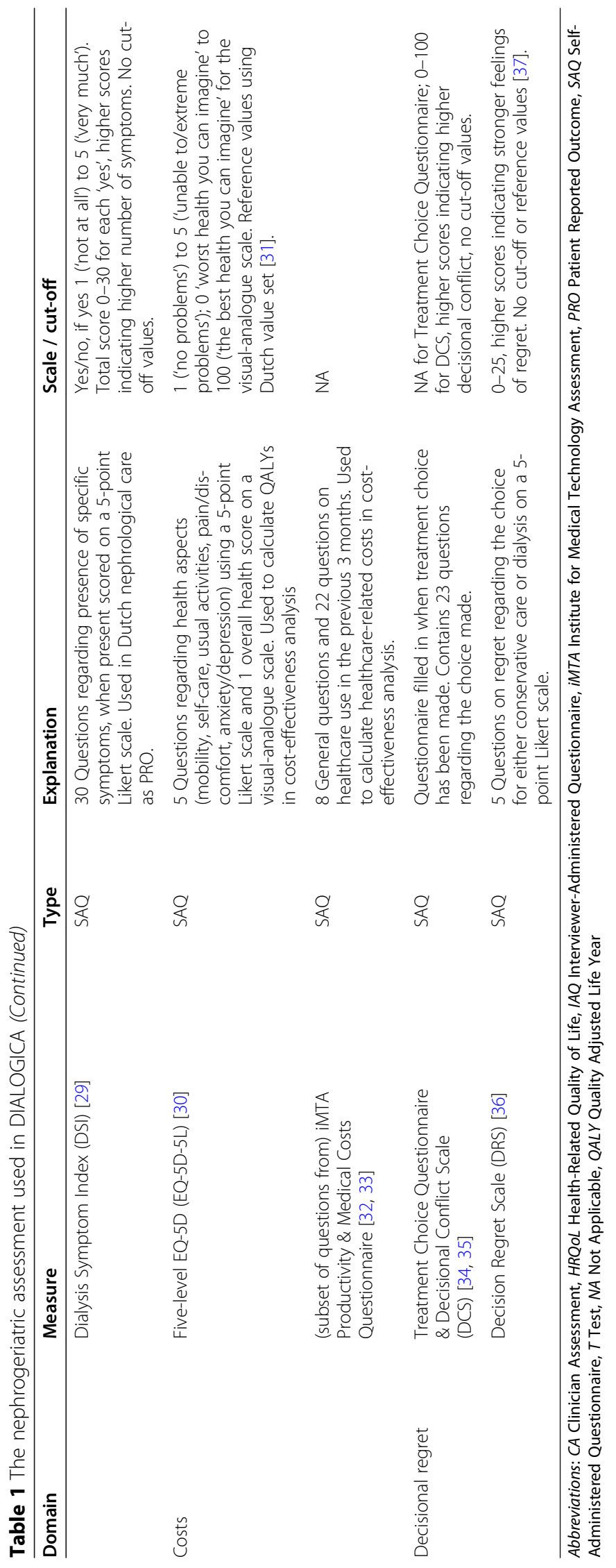


regarding the six functions of bathing, dressing, toileting, transferring, continence, and feeding. Secondly, the Instrumental Activities of Daily Living Scale by Lawton et al. measures eight domains of more complex independent living skills, such as handling finances, medication, and driving [15]. Thirdly, hand grip strength will be measured using a Jamar handheld dynamometer. Lastly, patients' fall risk will be assessed by both asking for fall frequency in the last year and their fear of falling, using a numeric rating scale.

\section{Psychological status}

Psychological status is assessed by using a total of five instruments, including three cognitive tests. The Montreal Cognitive Assessment scores different types of cognitive abilities, such as orientation, short-term memory, executive function, and visuospatial abilities [17]. The Six-item Cognitive Impairment Test is a fast and simple tool to screen for dementia, consisting of only six questions [18]. Finally, the Letter Digit Subtraction Test is a speed-dependent task that measures complex neuropsychological processes including visual scanning, mental flexibilities, sustained attention, psychomotor speed, and information processing [19].

Depression is assessed in two steps: first two casefinding questions ('Whooley-questions') are used, extended with the fifteen-item Geriatric Depression Scale if one or both of the two initial questions are positive $[21,22]$. The Life Orientation Test - Revised is a tenitem measure of optimism versus pessimism [23, 24, 38].

\section{Somatic status}

Somatic status will be evaluated by using three instruments. Treating clinicians will use the Clinical Frailty Score, which grades patients from 1 ('very fit') to 9 ('terminally ill') [25]. Comorbidity will be assessed with the Charlson Comorbidity Index [26]. Finally, the surprise question, a screening tool in which caregivers answer the question "Would you be surprised if this patient died within the next twelve months?", will be applied [39]. The Mini Nutritional Assessment - Short Form is used to assess the nutritional status of patients [27]. It is a well validated screening tool for the geriatric population consisting of 18 questions, categorising patients as 'wellnourished', 'at risk of malnutrition' or 'malnourished'.

\section{Social status}

Relevant social data (e.g. marital and residential status, biographic data such as educational attainment, and support by home care professionals and/or caregivers) is registered.

\section{HRQoL and symptoms}

Patients' HRQoL will be measured by the Twelve-item Short Form Health Survey (SF-12) [28]. Together with the Dialysis Symptom Index (DSI), it was selected as the patient reported outcome measures in Dutch nephrological care by the Dutch Kidney Patients Association, the Dutch Federation for Nephrology, Nefrovisie, and Leiden University Medical Center [29, 40]. The SF-12 and DSI were introduced for all Dutch patients on maintenance dialysis in 2018 [40]. The SF-12 consists of 12 questions regarding HRQoL and is the shorter version of the Short Form-36 (SF-36), the most widely used survey to assess HRQoL [28]. The SF-36 consists of eight domains: physical functioning, role-physical, bodily pain, general health, vitality, social function, role-emotional, and mental health. These domains are summarised in the Physical Component Summary Score and the Mental Component Summary Score. In the SF-12 these summary scores are calculated from the twelve most important items (explaining 90\% variance) of the SF-36 questionnaire [41]. As the average difference in summary scores between SF-12 and SF-36 is quite small, for timeefficiency reasons, the SF-12 can be used reliably in cohort studies [42]. The DSI is a set of 30 questions evaluating the severity of symptoms in patients with kidney failure (Table S1) [29]. Patients report the level of burden of the symptoms on a five-point Likert scale, ranging from 'not at all bothersome' to 'very bothersome'. Since these symptoms, such as nausea, energy loss, and shortness of breath, are common in patients with kidney failure and not specifically related to dialysis treatment, this questionnaire is also applicable to patients treated with CC.

\section{Costs}

For cost-effectiveness analyses, two questionnaires are used to investigate healthcare resources utilisation and patient costs. The Five-level EQ-5D (EQ-5D-5L) is a short and widely used questionnaire in both clinical and health-economic research as its scores can easily be translated into quality adjusted life years (QALYs), the primary outcome measure for most cost-effectiveness research [30,31]. It consists of five questions on domains of HRQoL, such as mobility, pain, and daily functioning. In addition, patients' and healthcare costs and costs with regard to productivity losses will be assessed with a subset of questions from the Institute for Medical Technology Assessment (iMTA) Productivity Cost Questionnaire (iPCQ) and the iMTA Medical Cost Questionnaire (iMCQ) [32, 33].

\section{Decisional regret}

Decisional regret regarding the choice for $\mathrm{CC}$ or dialysis, will be determined with the validated Decisional Regret Scale [36]. Multiple studies assessed the regret of patients to start dialysis with results ranging from $7.4 \%$ in a Dutch survey up to $61 \%$ in a Canadian study [43-46]. 
Currently, there is a lack of data regarding the decisional regret comparing CC with dialysis. An additional questionnaire (Treatment Choice \& Decisional Conflict Scale) regarding the treatment choice made will be added to gain more insight in the decisionmaking process regarding the choice between $\mathrm{CC}$ and dialysis $[34,35]$.

\section{Outcome variables}

The primary outcome parameter is HRQoL (Table 2). DIALOGICA will assess three secondary outcome parameters: clinical outcomes, cost-effectiveness, and decisional regret. The clinical outcomes that will be assessed are mortality, hospitalisation, functional status, cognitive functioning, and frailty. All outcomes are assessed with (repeated) measures during the first year of the second stage.

\section{HRQoL}

HRQoL is assessed by comparing repeated measurements of both the calculated Physical Component Summary Score and the Mental Component Summary Score of the SF-12 at the start of the second stage and after 3, 6 and 12 months after the start of the second stage.

\section{Clinical outcomes}

Mortality will be analysed as all-cause mortality within the first year of the second stage. The cause of death will also be categorised into seven categories, based on the United Kingdom Renal Registry, using ERA-EDTA codes (Table S2) [16, 47]. Hospitalisation will be analysed as all-cause hospitalisation within the first year of the second stage and each individual episode will be categorised into seven categories, using ICD-10 codes (Table S3) [48]. Functional status, cognitive functioning, and frailty will be repeated measures (at the start of the second stage and after 12 months) using their respective instruments, described in the previous paragraphs.

\section{Cost-effectiveness}

QALYs will be calculated using the EQ-5D-5L [30]. Total healthcare costs will be calculated using a subset of questions from the iPCQ and iMCQ [32, 33]. Costeffectiveness will be assessed as total costs per QALY using incremental cost-effectiveness ratio's (ICERs).

\section{Decisional regret}

Decisional regret will be measured using the Decisional Regret Scale, measured at 12 months after the start of the second stage only [36].

\section{Statistical analysis}

All statistical analyses will be performed using statistical software, such as SPSS and R. Univariable and multivariable regression analysis to correct for possible confounders will be used to compare groups. Longitudinal data will be analysed with linear and logistic mixed models and presented as estimated coefficients and odds ratios with 95\% confidence intervals. Cumulative incidence of hospitalisation and mortality will be reported in Kaplan Meier curves. A Cox proportional hazards model will be used to compare the rate of mortality and hospitalisation between groups. Overall costs and ICERs will be compared across the two groups using linear regression. Discounting, a mathematical procedure for adjusting future costs to their 'present day value', will be applied, as requested for all health economic evaluation exceeding a time frame of 1 year. To deal with missing data, multiple imputation by fully conditional specification will be applied.

Table 2 Study outcomes

\begin{tabular}{|c|c|c|c|}
\hline \multicolumn{3}{|l|}{ Outcomes } & \multirow{2}{*}{$\begin{array}{l}\text { Instruments } \\
\text { SF-12 physical and mental } \\
\text { component scores [28] }\end{array}$} \\
\hline Primary outcome & HRQoL & & \\
\hline \multirow[t]{7}{*}{ Secondary outcomes } & Clinical outcomes & Mortality (all-cause) & ERA-EDTA codes $[16,47]$ \\
\hline & & Hospitalisation (all-cause) & ICD-10 codes $[48]$ \\
\hline & & Functional status & Katz-ADL [14], Lawton-iADL [15] \\
\hline & & Cognitive functioning & MoCA [17], 6-CIT [18], LDST [20] \\
\hline & & Frailty & Clinical Frailty Scale [25] \\
\hline & Cost-effectiveness & & $\begin{array}{l}\text { ICERs, calculated using EQ-5D-5 L } \\
{[30] \text { and iPCQ/iMCQ }[32,33]}\end{array}$ \\
\hline & Decisional regret & & Decisional Regret Scale [36] \\
\hline
\end{tabular}

All outcomes are repeated measures during the first year of the second stage (Fig. 1)

Abbreviations: 6-CIT six-item Cognitive Impairment Test, EQ-5D-5L Five-level EQ-5D, ERA-EDTA European Renal Association - European Dialysis \& Transplant Organisation, $H R Q o L$ Health-Related Quality of Life, (i) ADL (Instrumental) Activities of Daily Living, ICD-10 International Statistical Classification of Diseases, 10th edition, ICER Incremental Cost-Effectiveness Ratio, iMCQ iMTA Medical Costs Questionnaire, iPCQ iMTA Productivity Cost Questionnaire, LDST Letter-Digit Substitution Test, MoCA Montreal Cognitive Assessment, QALY Quality Adjusted Life Year, SF-12 Twelve-item Short Form Health Survey 


\section{Sample size calculation}

For the primary outcome, we aim to have $80 \%$ power to detect a difference of 3.0 points in the SF-12 summary scores 12 months after the start of the second stage. To reject the null hypothesis of equal means with a standard deviation for both groups of 9.0 with a significance level (alpha) of 0.05 using a two-sided two-sample equalvariance Z-test, a required total sample size of 443 patients was calculated ( 89 patients on CC, 354 on dialysis, 1:4 ratio based on unpublished data from three Dutch centres). When taking into account a dropout rate of 10\%, 99 patients on CC and 394 on dialysis are needed, a total of 493 patients. Based on a study from the United States, we expected one third of patients to progress from stage one to two within 3 years, so a cohort of 1500 patients will be needed [49].

\section{Discussion}

With an ageing population with kidney failure, more patients will face the decisional moment whether to start dialysis or not. As the survival benefit of dialysis treatment in the geriatric population is debatable, focus has shifted towards HRQoL as primary outcome measure. The impact of dialysis on HRQoL of older patients is probably large, but current data comparing it to $\mathrm{CC}$ are both limited and biased, creating an urgent need for high-quality studies [7]. DIALOGICA will be the first large study to prospectively assess the differences between patients choosing $\mathrm{CC}$ or dialysis. With a total follow-up of up to 4 years, outcome parameters can be assessed in more detail. Biological age, which also takes factors such as functional status, cognitive functioning, and somatic functioning into account, might influence these outcomes more than calendar age. This study will help to determine individual patient characteristics to identify patients less likely to benefit from dialysis initiation. This will support patients with kidney failure and their nephrologists in making a well-informed and shared decision when discussing renal replacement therapy. To do so, DIALOGICA combines a practical test set of well-validated questionnaires and assessments that can be performed in less than 1 hour per patient. With better identification of patients who might not benefit from dialysis, a significant reduction in costs for treatment of kidney failure can be achieved if these patients choose for $\mathrm{CC}$, since $\mathrm{CC}$ has far lower annual treatment costs compared to dialysis [6].

DIALOGICA has an observational study design instead of a randomised controlled design. We deemed the patient's choice between CC and dialysis too fundamentally different to let it be determined by fate. Randomised studies for treatment modalities have been shown to be challenging in patients with kidney failure in general as they have large and different implications for patients' daily life. For example, a previous Dutch study that tried to randomise patients between haemodialysis and peritoneal dialysis failed and the choice whether or not to start dialysis arguably has even more impact [50]. To our knowledge, only one study comparing $\mathrm{CC}$ and dialysis is currently recruiting patients using a randomised design [51]. The implication of the observational design of DIALOGICA is that it is more sensitive to confounding by indication, since observed and unobserved variables can influence outcome of treatment. However, selective inclusion into randomised controlled studies can also lead to poor external validity of their results and an observational study may provide a better reflection of daily clinical practice. To account for the influence of the observed variables on treatment outcome and thus to limit confounding by indication, extensive correction for confounding will be applied, using a large set of patients' characteristics.

Treating physicians and patients are not blinded for the results of the NGA, because this could hamper appropriate care for newly diagnosed geriatric impairments. Moreover, as NGAs are becoming standard of care in most Dutch centres, it is ethically undesirable to withhold the results of the NGA from treating physicians and participating patients. Since the results of the NGA might influence the treatment decision both for patients and for treating physicians this can introduce selection bias between patients choosing for CC and dialysis, and could be considered a limitation. Where needed, correction for baseline NGA discrepancies will be applied.

\section{Conclusion}

Data on relevant outcomes are needed to answer the question whether $\mathrm{CC}$ is a serious alternative to dialysis in (a subgroup of) older patients with kidney failure. In the upcoming years, DIALOGICA will investigate the effect of CC on HRQoL, clinical outcomes, and costeffectiveness in comparison to dialysis in this population, generating more insight to aid doctors and patients in the shared decision making process.

\section{Supplementary Information}

The online version contains supplementary material available at https://doi. org/10.1186/s12882-021-02235-y.

Additional file 1: Table S1. The Dialysis Symptom Index.

Additional file 2: Table S2. Categories for mortality, using ERA-EDTA codes, based on the United Kingdom Renal Registry.

Additional file 3: Table S3. Categories for hospitalisation, using ICD-10 codes.

\section{Abbreviations}

CC: Conservative Care; CKD-EPI: Chronic Kidney Disease EPIdemiology Collaboration; DIALOGICA: DIALysis or not - Outcomes in older kidney 
patients with GerlatriC Assessment; DSI: Dialysis Symptom Index; eGFR: Estimated Glomerular Filtration Rate; EQ-5D-5L: Five-level EQ-5D questionnaire; HRQoL: Health-Related Quality of Life; ICER: Incremental CostEffectiveness Ratio; iMCQ: iMTA Medical Consumption Questionnaire; iMTA: Institute for Medical Technology Assessment; iPCQ: iMTA Productivity Cost Questionnaire; NGA: NephroGeriatric Assessment; SF-12/- 36: 12/36Item Short Form Health Survey; QALY: Quality adjusted life year

\section{Acknowledgements}

DIALOGICA study group members: JB van der Net, Albert Schweitzer Hospital Dordrecht; TT Cnossen and K. Goossens, Amphia Hospital Breda; HP Krepel, Bravis Hospital Roosendaal; SJJ Logtenberg, Diakonessenhuis Utrecht; CR Susanto, Elkerliek Hospital; D Severs and HA Polinder-Bos, Erasmus Medical Center Rotterdam; MA Siezenga and R Bogers, Hospital Gelderse Vallei Ede; EK Hoogeveen and APM Kerckhoffs, Jeroen Bosch Hospital 's Hertogenbosch; T Cornelis, Jessa Hospital Hasselt (Belgium); JT Jonker, Leiden University Medical Center; JMH Joosten and EJR Litjens, Maastricht University Medical Center; AY Adema and A. Bontemps-Visser, Medical Center Leeuwarden; RJ Bosma and MDM Romijn, Meander Medical Center Amersfoort; H Boom, Reinier de Graaf Gasthuis Delft; G van Kempen, Saxenburgh Group Hardenberg; HHTI Klein, Slingeland Hospital Doetinchem; JD Snoep and MHPJ Schuurmans, Tergooi Hilversum; FL Nauta, Treant Zorggroep Emmen; CFM Franssen, University Medical Center Groningen; FM Molenaar, University Medical Center Utrecht; I Wauters, ZorgSaam Hospital Terneuzen.

\section{Authors' contributions}

$A A, W B, M E, S M, M D, B J, A E, C V$, and $M B$ designed the protocol of the present study. $M O, A A, W B, M E, S M, M D, B J$, and $M B$ are involved in the conductance of the study. $M O, A A$, and $M B$ wrote the first draft of the manuscript. All authors critically edited the manuscript and approved the final version.

\section{Funding}

This study is supported by Leading the Change, a Dutch health care efficiency evaluation project by Zorgevaluatie Nederland. The sponsor did not play a role in study design and in the drafting of this paper.

\section{Availability of data and materials}

Not applicable.

\section{Ethics approval and consent to participate}

Primary ethical approval was obtained from the medical research ethics committee of the The Hague region (METC Zuidwest Holland, a joint committee for the HagaZiekenhuis, Haaglanden Medical Center and Reinier de Graaf Gasthuis Delft hospitals) on May 24th 2019 (reference number 19071). Local medical research ethics committees in participating centres will also be asked for local ethical approval. The study is registered in the Netherlands Trial Register under NL-8352. The study is conducted according to the principles of the Declaration of Helsinki and the ICH-GCP guidelines, including requirement of written informed consent upon study participation.

\section{Consent for publication}

Not applicable.

\section{Competing interests}

WB received grant support from Zilveren Kruis Insurance, outside the submitted work. The work on this study by MD was supported by a grant from the Dutch Kidney Foundation (16OKG12). The work on this study by CV was supported by a grant from the Nephrosearch Foundation. The remaining authors declare they have no competing interests.

\section{Author details}

${ }^{1}$ Department of Internal Medicine, Leiden University Medical Center, Albinusdreef 2, 2333 ZA Leiden, The Netherlands. ${ }^{2}$ Department of Nephrology and Hypertension, University Medical Center Utrecht, Utrecht, The Netherlands. ${ }^{3}$ Department of Internal Medicine, St Antonius Hospital, Nieuwegein, The Netherlands. ${ }^{4}$ Department of Geriatrics, University Medical Center Utrecht, Utrecht, The Netherlands. ${ }^{5}$ Department of Gerontology and Geriatrics, Leiden University Medical Center, Leiden, The Netherlands. ${ }^{6}$ Department of Clinical Epidemiology, Leiden University Medical Center, Leiden, The Netherlands. ${ }^{7}$ Department of Nephrology, Amsterdam
Cardiovascular Sciences, Amsterdam University Medical Center, Amsterdam The Netherlands. ${ }^{8}$ Department of Nephrology, Haga Hospital, The Hague, The Netherlands.

Received: 10 December 2020 Accepted: 6 January 2021

Published online: 23 January 2021

\section{References}

1. Nefrovisie. http://www.nefrovisie.nl/nefrodata/. Accessed 20 July 2020.

2. Stichting Nefrovisie, personal communications, based on data for 20132018 from Nefrodata.

3. Verberne WR, Geers ABMT, Jellema WT, et al. Comparative survival among older adults with advanced kidney disease managed conservatively versus with dialysis. Clin J Am Soc Nephrol. 2016;11(4):633-40.

4. Van Loon IN, Goto NA, Boereboom FTJ, et al. Quality of life after the initiation of dialysis or maximal conservative management in elderly patients: a longitudinal analysis of the geriatric assessment in OLder patients starting Dialysis (GOLD) study. BMC Nephrol. 2019;20(1):108.

5. Lee MB, Bargman JM. Survival by Dialysis modality - who cares? Clin J Am Soc Nephrol. 2016;11(6):1083-7.

6. Verberne WR, Dijkers J, Kelder JC, et al. Value-based evaluation of dialysis versus conservative care in older patients with advanced chronic kidney disease: a cohort study. BMC Nephrol. 2018;19(1):205

7. Verberne WR, van den Wittenboer ID, Voorend CGN, et al. Healthrelated quality of life and symptoms of conservative care versus dialysis in patients with end-stage kidney disease: a systematic review. Nephrol Dial Transplant. 2020

8. Kallenberg $\mathrm{MH}$, Kleinveld HA, Dekker FW, et al. Functional and cognitive impairment, frailty, and adverse health outcomes in older patients reaching ESRD - a systematic review. Clin J Am Soc Nephrol. 2016;11(9):1624-39.

9. Brown EA, Farrington K. Geriatric assessment in advanced kidney disease. Clin J Am Soc Nephrol. 2019;14(7):1091-3.

10. Mohnen SM, van Oosten MJM, Los J, et al. Healthcare costs of patients on different renal replacement modalities - Analysis of Dutch health insurance claims data. PLoS One. 2019;14(8):e0220800.

11. Nederlands Trial Register. Identifier NL6519, nephro-geriatric care pathway. Accessed 10 July 2020

12. Nederlands Trial Register. Identifier NL7104, optimizing access surgery in senior hemodialysis patients. Accessed 10 July 2020

13. Nederlands Trial Register. Identifier NL7933, Dutch nOcturnal and hoME dialysis study to improve clinical outcomes. Accessed 10 July 2020.

14. Katz S, Ford AB, Moskowitz RW, et al. Studies of illness in the aged. The index of ADL: a standardized measure of biological and psychosocial function. JAMA. 1963;185:914-9.

15. Lawton MP, Brody EM. Assessment of older people: self-maintaining and instrumental activities of daily living1. The Gerontologist. 1969;9(3_ Part_1):179-86.

16. Spruit MA, Sillen MJ, Groenen MT, Wouters EF, Franssen FM. New normative values for handgrip strength: results from the UK Biobank. J Am Med Dir Assoc. 2013:14(10):775.e5-11.

17. Nasreddine ZS, Phillips NA, Bédirian V, et al. The Montreal cognitive assessment, MoCA: a brief screening tool for mild cognitive impairment. J Am Geriatr Soc. 2005;53(4):695-9.

18. Katzman R, Brown T, Fuld $P$, et al. Validation of a short orientationmemory-concentration test of cognitive impairment. Am J Psychiatry. 1983;140(6):734-9.

19. Jolles J, Houx PJ, Van Boxtel MPJ, et al. The Maastricht aging study: determinants of cognitive aging. Maastricht: Neuropsych Publishers Maastricht; 1995.

20. Van der Elst W, van Boxtel MP, van Breukelen GJ, et al. The letter digit substitution test: normative data for 1,858 healthy participants aged 24-81 from the Maastricht aging study (MAAS): influence of age, education, and sex. J Clin Exp Neuropsychol. 2006:28(6):998-1009.

21. Yesavage JA, Sheikh J. 9/geriatric depression scale (GDS). Clin Gerontol. 1986:5(1-2):165-73.

22. Whooley MA, Avins AL, Miranda J, et al. Case-finding instruments for depression. Two questions are as good as many. J Gen Intern Med. 1997: 12(7):439-45. 
23. Scheier MF, Carver CS, Bridges MW. Distinguishing optimism from neuroticism (and trait anxiety, self-mastery, and self-esteem): a reevaluation of the life orientation test. J Pers Soc Psychol. 1994;67(6):1063-78.

24. Glaesmer H, Rief W, Martin A, et al. Psychometric properties and populationbased norms of the life orientation test revised (LOT-R). Br J Health Psychol. 2012;17(2):432-45.

25. Rockwood K, Song X, Macknight C, et al. A global clinical measure of fitness and frailty in elderly people. CMAJ. 2005;173(5):489-95.

26. Charlson ME, Pompei P, Ales KL, et al. A new method of classifying prognostic comorbidity in longitudinal studies: development and validation. J Chronic Dis. 1987;40(5):373-83.

27. Rubenstein LZ, Harker JO, Salvà A, et al. Screening for undernutrition in geriatric practice: developing the short-form mini-nutritional assessment (MNA-SF). J Gerontol A Biol Sci Med Sci. 2001;56(6):M366-72.

28. Ware JE, Snow KK, Kosinski M, et al. SF-36 health survey: manual and interpretation guide: Health Institute, New England Medical Center; 1997.

29. Weisbord SD, Fried LF, Arnold RM, et al. Development of a symptom assessment instrument for chronic hemodialysis patients: the Dialysis symptom index. J Pain Symptom Manag. 2004;27(3):226-40.

30. Herdman M, Gudex C, Lloyd A, et al. Development and preliminary testing of the new five-level version of EQ-5D (EQ-5D-5L). Qual Life Res. 2011;20(10):1727-36.

31. Versteegh MM, Vermeulen KM, Evers SMAA, et al. Dutch tariff for the fivelevel version of EQ-5D. Value Health. 2016;19(4):343-52.

32. Institute for Medical Technology Assessment, Productivity and Health Research Group. Handleiding iMTA Medical Cost Questionnaire (iMCQ). Rotterdam: iMTA, Erasmus University Rotterdam; 2018. https://www.imta.nl/ questionnaires/. Accessed Jun 72020

33. Bouwmans $C$, Krol M, Severens $H$, et al. The iMTA productivity cost questionnaire: a standardized instrument for measuring and valuing healthrelated productivity losses. Value Health. 2015;18(6):753-8.

34. O'Connor AM. Validation of a decisional conflict scale. Med Decis Mak. 1995; 15(1):25-30

35. Koedoot N, Molenaar S, Oosterveld P, et al. The decisional conflict scale: further validation in two samples of Dutch oncology patients. Patient Educ Couns. 2001;45(3):187-93.

36. Brehaut JC, O'Connor AM, Wood TJ, et al. Validation of a decision regret scale. Med Decis Mak. 2003;23(4):281-92.

37. Becerra Pérez MM, Menear M, Brehaut JC, et al. Extent and predictors of decision regret about health care decisions: a systematic review. Med Decis Mak. 2016;36(6):777-90.

38. Zawadzka B, Zawadzka S, Sułowicz W, et al. Cooperation in treatment as an Indicator of adaptation of kidney transplant patients to chronic therapy. Transplant Proc. 2016;48(5):1598-603.

39. Cohen LM, Ruthazer R, Moss AH, et al. Predicting six-month mortality for patients who are on maintenance hemodialysis. Clin J Am Soc Nephrol. 2010;5(1):72-9.

40. Van der Willik EM, Meuleman Y, Prantl K, et al. Patient-reported outcome measures: selection of a valid questionnaire for routine symptom assessment in patients with advanced chronic kidney disease - a four-phase mixed methods study. BMC Nephrol. 2019;20(1):344.

41. Gandek B, Ware JE, Aaronson NK, et al. Cross-validation of item selection and scoring for the SF-12 health survey in nine countries: results from the IQOLA project. International quality of life assessment. J Clin Epidemiol. 1998:51(11):1171-8.

42. Loosman WL, Hoekstra T, van Dijk S, et al. Short-form 12 or short-form 36 to measure quality-of-life changes in dialysis patients? Nephrol Dial Transplant. 2015;30(7):1170-6.

43. Berkhout-Byrne N, Gaasbeek A, Mallat MJK, et al. Regret about the decision to start dialysis: a cross-sectional Dutch national survey. Neth J Med. 2017; 75(6):225-34.

44. Davison SN. End-of-life care preferences and needs: perceptions of patients with chronic kidney disease. Clin J Am Soc Nephrol. 2010;5(2):195-204.

45. Tan EGF, Teo I, Finkelstein EA, et al. Determinants of regret in elderly dialysis patients. Nephrology. 2019;24(6):622-9.

46. Saeed F, Ladwig SA, Epstein RM, et al. Dialysis regret: prevalence and correlates. Clin J Am Soc Nephrol. 2020;15(7):957-63.

47. ERA-EDTA Registry: ERA-EDTA Registry Annual Report 2017. Amsterdam UMC, location AMC, Department of Medical Informatics, Amsterdam, the Netherlands, 2019

48. World Health Organization. The ICD-10 classification of mental and behavioural disorders: diagnostic criteria for research. Geneva: World Health Organization; 1993.
49. Kurella Tamura M, Desai M, Kapphahn Kl, et al. Dialysis versus medical management at different ages and levels of kidney function in veterans with advanced CKD. J Am Soc Nephrol. 2018;29(8):2169-77.

50. Korevaar JC, Feith GW, Dekker FW, et al. Effect of starting with hemodialysis compared with peritoneal dialysis in patients new on dialysis treatment: a randomized controlled trial. Kidney Int. 2003;64(6):2222-8.

51. ISRCTN Registry. Identifier ISRCTN17133653, The prepare multi-morbid older people for end-stage kidney disease trial Accessed 12 July 2020.

\section{Publisher's Note}

Springer Nature remains neutral with regard to jurisdictional claims in published maps and institutional affiliations.
Ready to submit your research? Choose BMC and benefit from:

- fast, convenient online submission

- thorough peer review by experienced researchers in your field

- rapid publication on acceptance

- support for research data, including large and complex data types

- gold Open Access which fosters wider collaboration and increased citations

- maximum visibility for your research: over $100 \mathrm{M}$ website views per year

At BMC, research is always in progress.

Learn more biomedcentral.com/submissions 